\title{
miR-296-3p, miR-298-5p and their downstream networks are causally involved in the higher resistance of mammalian pancreatic a cells to cytokine-induced apoptosis as compared to $\beta$ cells
}

Davide Barbagallo ${ }^{1+}$, Salvatore Piro ${ }^{2 \dagger}$, Angelo G Condorelli ${ }^{1}$, Loriana G Mascali ${ }^{2}$, Francesca Urbano ${ }^{2}$, Nunziatina Parrinello², Adelina Monello², Luisa Statello', Marco Ragusa' ${ }^{1}$, Agata M Rabuazzo², Cinzia Di Pietro ${ }^{1}$, Francesco Purrello ${ }^{2^{*}}$ and Michele Purrello ${ }^{1^{*}}$

\begin{abstract}
Background: The molecular bases of mammalian pancreatic a cells higher resistance than $\beta$ to proinflammatory cytokines are very poorly defined. MicroRNAs are master regulators of cell networks, but only scanty data are available on their transcriptome in these cells and its alterations in diabetes mellitus.

Results: Through high-throughput real-time $P C R$, we analyzed the steady state microRNA transcriptome of murine pancreatic a (aTC1-6) and $\beta$ ( $\beta T C 1)$ cells: their comparison demonstrated significant differences. We also characterized the alterations of aTC1-6 cells microRNA transcriptome after treatment with proinflammatory cytokines. We focused our study on two microRNAs, miR-296-3p and miR-298-5p, which were: (1) specifically expressed at steady state in aTC1-6, but not in BTC1 or INS-1 cells; (2) significantly downregulated in aTC1-6 cells after treatment with cytokines in comparison to untreated controls. These microRNAs share more targets than expected by chance and were co-expressed in aTC1-6 during a 6-48 h time course treatment with cytokines. The genes encoding them are physically clustered in the murine and human genome. By exploiting specific microRNA mimics, we demonstrated that experimental upregulation of miR-296-3p and miR-298-5p raised the propensity to apoptosis of transfected and cytokine-treated aTC1-6 cells with respect to aTC1-6 cells, treated with cytokines after transfection with scramble molecules. Both microRNAs control the expression of IGF1Rß, its downstream targets phospho-IRS-1 and phospho-ERK, and TNFa. Our computational analysis suggests that MAFB (a transcription factor exclusively expressed in pancreatic a cells within adult rodent islets of Langerhans) controls the expression of miR-296-3p and miR-298-5p.

(Continued on next page)
\end{abstract}

\footnotetext{
*Correspondence: fpurrell@unict.it; purrello@unict.it

${ }^{\dagger}$ Equal contributors

${ }^{2}$ Dipartimento di BioMedicina Clinica e Molecolare, Università di Catania, Catania, EU 95122, Italy

${ }^{1}$ Dipartimento Gian Filippo Ingrassia, Unità di BioMedicina Molecolare Genomica e dei Sistemi Complessi, Genetica, Biologia Computazionale, Università di Catania, Catania, EU 95123, Italy

Full list of author information is available at the end of the article
} 
(Continued from previous page)

Conclusions: Altogether, high-throughput microRNA profiling, functional analysis with synthetic mimics and molecular characterization of modulated pathways strongly suggest that specific downregulation of miR-296-3p and miR-298-5p, coupled to upregulation of their targets as IGF1Rß and TNFa, is a major determinant of mammalian pancreatic a cells resistance to apoptosis induction by cytokines.

Keywords: Mammalian pancreatic a and $\beta$ cells, microRNA transcriptome, Proinflammatory cytokines, Apoptosis, Cellular networks, Diabetes mellitus

\section{Background}

Insulitis is an inflammation of pancreatic Langerhans islets, which is known to precede the onset of diabetes mellitus (DM) $[1,2]$. Post-insulitis decrease of pancreatic $\beta$ cells is a major hallmark of both type 1 (T1DM) and type 2 diabetes mellitus (T2DM) [3-5]. It is associated to $\alpha$ cells dysfunctions and high glucagon secretion, which contribute to chronic hyperglycemia and ensuing clinical outcomes in DM [6,7]. Accordingly, efforts to increase our knowledge on the biomolecular mechanisms regulating proliferation, physiopathological functions, and apoptosis of $\alpha$ cells will likely result in improved medical approaches to the disease. The pathways leading to mammalian $\beta$ cell apoptosis, induced by proinflammatory cytokines, are complex but sufficiently known $[8,9]$. On the contrary, the molecular bases of $\alpha$ cells higher resistance than $\beta$ to the same cues are still largely uncharacterized [10-12]. Pancreatic $\alpha$ and $\beta$ cells share common endocrine precursors $\left(\mathrm{Ngn}^{+}\right.$cells), but upon differentiation they respond differently to external stimuli as proinflammatory cytokines, glucagon-like peptide 1 (GLP1), and inhibitors of dipeptidyl peptidase-4 (DPP-4) [12-14]. MicroRNAs (miRNAs) are small (19-25 nucleotides) noncoding RNAs, which control gene expression mainly at the post-transcriptional level: miRNAs have been shown to be master regulators of cell networks $[15,16]$. Many miRNAs are involved in DM physiopathology: for instance, miR-375 controls $\beta$ cell mass and insulin secretion [17]; miR-21 and miR-146a are involved in $\beta$-cell apoptosis [18]; miR-30d promotes insulin synthesis and protects $\beta$ cells from damage by proinflammatory cytokines [19]; miR126 is responsible for impaired angiogenetic signaling in DM patients [20]. However, there are no high-throughput (HT) published data on $\alpha$ cells miRNA transcriptome at steady state, its comparison with $\beta$ cells steady state miRNA transcriptome, and its alterations following treatment with cytokines. To discover new physiopathologic regulatory mechanisms, specific of cytokine-treated pancreatic cells, we profiled global miRNAs expression in two mouse pancreatic cell lines ( $\alpha \mathrm{TC} 1-6$ and $\beta \mathrm{TC} 1)$ at steady state and in $\alpha \mathrm{TC} 1-6$ after treatment with proinflammatory cytokines IFN- $\gamma$, IL-1 $\beta$, TNF- $\alpha$. This analysis brought to the identification of: (1) differentially expressed (DE) miRNAs between $\alpha \mathrm{TC} 1-6$ and $\beta \mathrm{TC} 1$ at steady state; (2) DE miRNAs between $\alpha$ TC1- 6 treated with cytokines and matched untreated controls. To insert our data in the appropriate biological context, we reconstructed the molecular networks regulated at steady state by DE miRNAs in $\alpha$ and $\beta$ cells. Our results demonstrate that these networks are remarkably different: very likely, they increase $\alpha$ cells resistance to apoptosis and negatively interfere with pancreatic $\beta$ cells viability after exposure to cytokines.

\section{Results \\ Apoptosis induction by cytokines in aTC1- 6 and $\beta$ TC1 cells}

To verify the differential response of $\alpha \mathrm{TC} 1-6$ and $\beta \mathrm{TC} 1$ cells to treatment with cytokines, we assayed their propensity to undergo apoptosis during a time course experiment (6-24-48 h after treatment, PT). The number of apoptotic $\alpha$ TC1-6 cells did not significantly vary with respect to controls for the entire time course (Figure 1A), demonstrating that in our system $\alpha$ cells appear to withstand apoptosis induction by cytokines; on the contrary, $\beta \mathrm{TC} 1$ cells are clearly more susceptible to treatment (Figure 1B).

\section{Steady state miRNA transcriptome profiles of aTC1-6 and $\beta$ TC1 cells}

To identify miRNAs potentially responsible for $\alpha \mathrm{TC} 1-6$ resistance to cytokines, we analyzed the steady state miRNA transcriptome of $\alpha \mathrm{TC} 1-6$ and $\beta \mathrm{TC} 1$ cells. At steady state, 23 miRNAs were exclusively expressed in $\alpha$ TC1-6 ( $\alpha$-miRNAs), while 26 were expressed only in $\beta$ TC1 ( $\beta$-miRNAs); 50 miRNAs resulted significantly more expressed in $\alpha \mathrm{TC} 1-6$ than in $\beta \mathrm{TC} 1$, whereas 74 were significantly more expressed in $\beta \mathrm{TC} 1$ compared to aTC1-6 (Limma test, Benjamini-Hochberg adjusted p-values < 0.05) (see Additional file 1). Their assignment to specific families is shown in Additional files 2 and 3.

\section{Treatment with cytokines alters aTC1-6 miRNA transcriptome profiles}

After treatment with cytokines for $48 \mathrm{~h}, 3$ miRNAs (miR-146a, miR-203, miR-298-5p) were significantly differentially expressed in $\alpha \mathrm{TC} 1-6$ as compared to matched untreated controls (Limma test, Benjamini-Hochberg adjusted p-values <0.05) (see Additional file 4). Their 


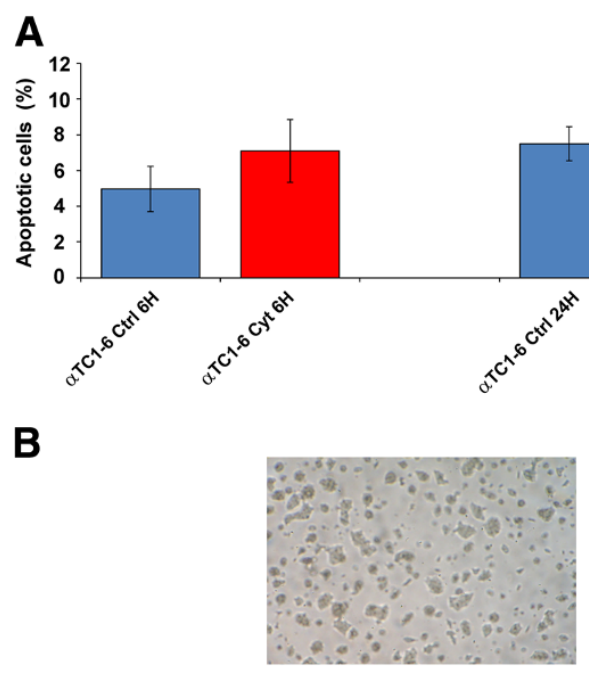

BTC1 Ctrl 24H
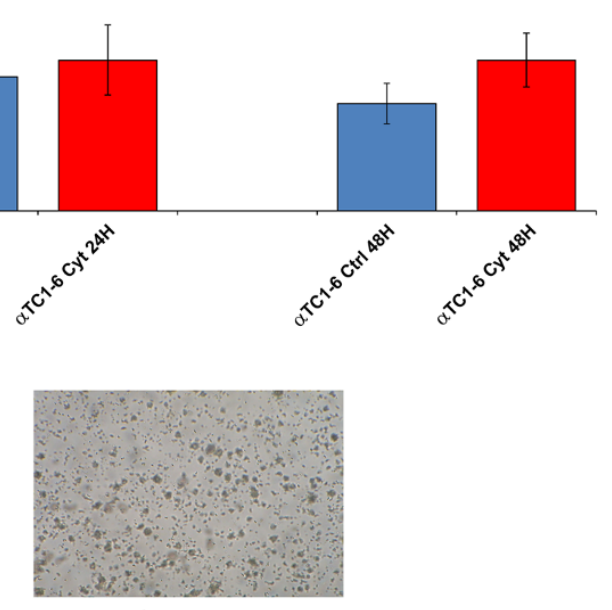

BTC1 Cyt 24H

Figure 1 Apoptosis of aTC1-6 and $\beta$ TC1 after treatment with cytokines. (A) Annexin $V$ flow cytometric analysis of apoptosis in aTC1-6 treated with IFN- $\gamma, I L-1 \beta$, TNF-a for $6,24,48 \mathrm{~h}$ and in matched untreated controls. Values represent the percentage of apoptotic cells. Data are presented as mean \pm S.D. of three independent experiments $(n=3)$. (B) Microphotographs of BTC1 at steady state (left) and $24 \mathrm{~h}$ PT (right). Cell shrinkage and irregular morphology are evident in $\beta T C 1$ after $24 \mathrm{~h}$ of treatment. Representative pictures are shown from three independent experiments $(n=3)$.

assignment to specific families is shown in Additional file 5 .

\section{MiRNAs 296-3p and 298-5p are reliable candidates for involvement in aTC1-6 higher resistance than $\beta$ cells to apoptosis induction by cytokines}

To identify miRNAs whose functions could explain the differential response to cytokines of pancreatic $\alpha$ and $\beta$ cells, we specifically focused our attention on miR-296$3 p$ and miR-298-5p. Both miRNAs are expressed at steady state only in $\alpha \mathrm{TC} 1-6$, but are not synthesized in BTC1 (Figure 2A); both are part of the imprinted Gnas/ GNAS clusters in mice and humans and share more targets than expected by chance ( 44 versus 33 , respectively; $\mathrm{p}=0.0485, \chi^{2}$-test), even though their seed regions are different: this suggests common regulatory functions. Single TaqMan gene expression assays (STAs) during a time course analysis (6-12-24-48 h) showed a highly significant downregulation of miR-296-3p in $\alpha$ TC1- 6 cells at 24 and $48 \mathrm{~h} \mathrm{PT}$, compared to matched untreated controls (Student's $t$-test, Bonferroni adjusted p-value < 0.01). Mir-298-5p resulted significantly downregulated starting at $12 \mathrm{~h}$ PT and reached a highly significant downregulation at $48 \mathrm{~h} \mathrm{PT}$, compared to matched untreated controls: Student's $t$-test, Bonferroni adjusted pvalues, were $<0.05$ and $<0.01$, respectively (Figure $2 \mathrm{~B}$ ). Both miRNAs were co-expressed in $\alpha$ TC1- 6 cells throughout the entire experimental time course ( $r$-value $=0.88$, pvalue $=1.15 \mathrm{e}-08$, Pearson's correlation test) (see Additional file 6). STAs confirmed that they are not expressed either in $\beta$ TC1 or INS-1 cells.
Genomics of genes encoding miR-296-3p, miR-298-5p, Nespas and identification of upstream CpG islands Genes encoding miRNAs 296-3p and 298-5p are clustered in a genomic region, which also comprises the gene for the noncoding transcript Nespas and is imprinted in mice and humans [21]. Sequences of mature miR-296-3p are $100 \%$ conserved between rodents and humans, whereas those of miR-298-5p are 74\% identical. Analysis of this region through UCSC browser revealed the presence of two clusters of $\mathrm{CpG}$ islands: (i) one comprises two $\mathrm{CpG}$ islands, from 17.5 to $18.8 \mathrm{~kb}$ upstream the first nucleotide of pre-miR-296, and is located 9.2 and $10 \mathrm{~Kb}$ downstream Nespas transcription start site (TSS); (ii) the other is made of three CpG islands from 30.1 to $33.6 \mathrm{~Kb}$ upstream the first nucleotide of pre-miR-296 and is located 1.8-5 kb upstream Nespas TSS (see Additional file 7). MatInspector revealed a putative Nespas promoter located 500 bp upstream-100 bp downstream its TSS.

aTC1-6 transfection with mimics of miR-296-3p and miR298-5p increases apoptosis levels induced by cytokines

To precisely define miR-296-3p and miR-298-5p biological functions, we compared apoptosis levels of $\alpha \mathrm{TC} 1-6$ cells, transfected with either one or both miRNA mimics and treated with cytokines for $6,24,48 \mathrm{~h}$ after transfection (AT), with those of scramble-transfected $\alpha \mathrm{TC} 1-6$ cells treated with cytokines by following a similar protocol. The percentage of apoptotic $\alpha \mathrm{TC} 1-6$ cells after transfection with mimics of miR-296-3p was comparable to scrambletransfected controls during the entire time course treatment. On the other hand, transfection with mimics of 


\section{A}

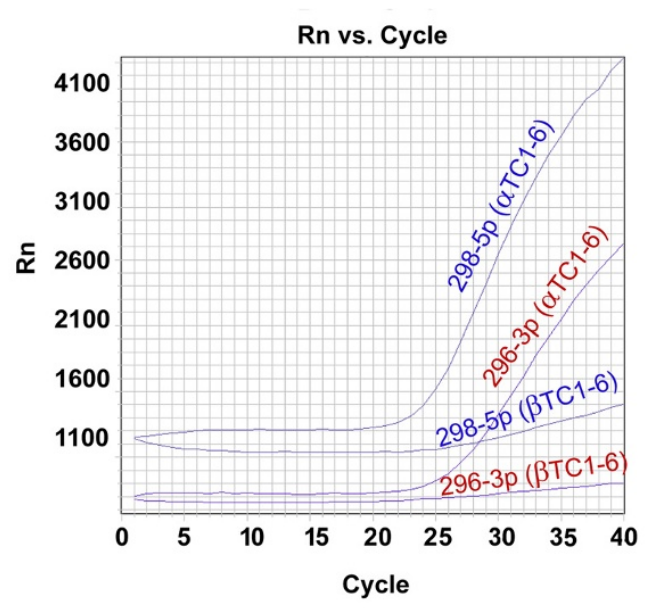

B mmu-miR-296-3p
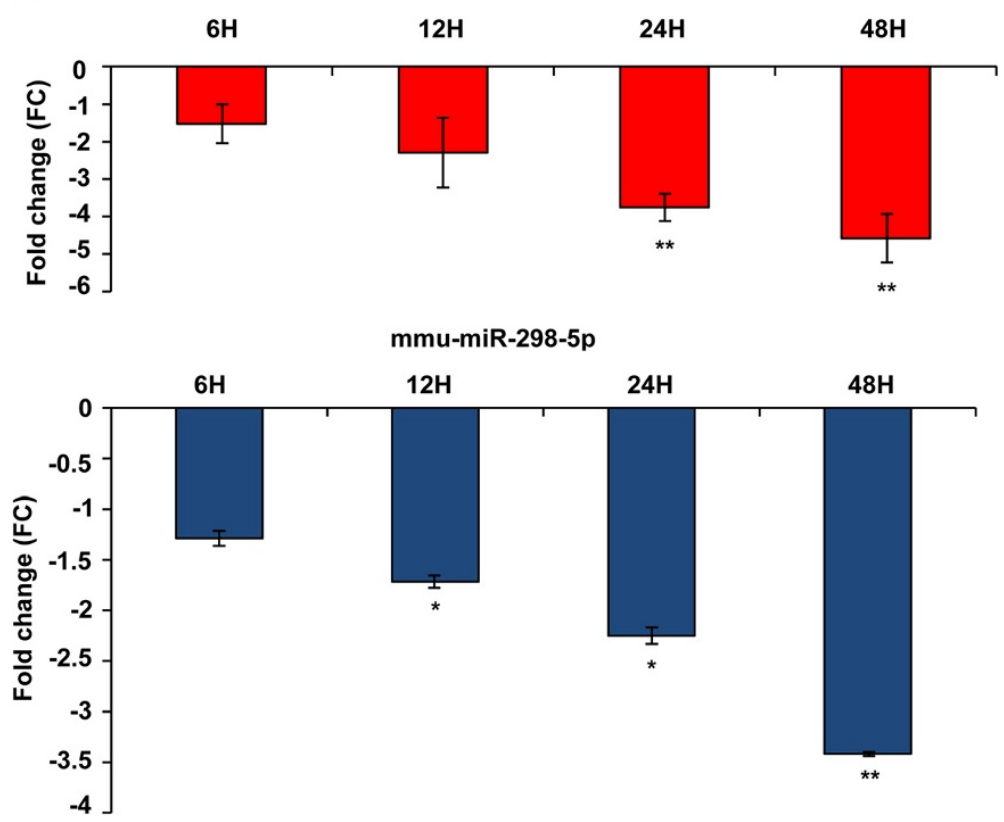

Figure 2 Expression of miR-296-3p and miR-298-5p in aTC1-6 and $\beta$ TC1. (A) Real-time PCR amplification plot of miR-296-3p and miR-298-5p in aTC1-6 and BTC1 at steady state. Note that both miRNAs are not expressed in $\beta T C 1$. Plot image is representative of three independent experiments ( $n=3$ ). (B) Gene expression fold changes of miR-296-3p and miR-298-5p in aTC1-6 at 6, 12, 24, 48 h PT, relative to matched untreated cells. MiRNAs expression was measured by quantitative real-time PCR. MiR-26a was used as endogenous control. Data are reported as mean \pm S.D. of three independent experiments $(n=3) .{ }^{*} p$-value $<0.05 ;{ }^{* *} p$-value $<0.01$ (Student's $t$-test, Bonferroni correction).

miR-298-5p or of both miR-296-3p and miR-298-5p increased in a highly significant manner the number of aTC1-6 apoptotic cells, compared to matched scrambletransfected controls: 1.5 and more than 2.5 folds at $24 \mathrm{~h}$ PT, respectively (Tukey HSD post-hoc one-way ANOVA test, p-value $<0.01$ ) (Figure 3).

\section{Identification of miR-296-3p and miR-298-5p targets}

To characterize the networks regulated by miRNAs 296$3 p$ and 298-5p, we computationally searched their validated and predicted targets. We identified 1 validated target of miR-296-3p; 5 validated targets of miR-298-5p; 207 predicted targets of miR-296-3p; 707 predicted targets of miR-298-5p. We focused our attention on 7 targets of miR-296-3p, 4 of miR-298-5p, 2 common to both miRNAs: they were chosen according to their involvement in apoptosis, cell cycle progression, cell differentiation and hormone secretion (see Additional file 8). Among them, Bcl2, Ccna2, Irs2, Nr4a2 are transcriptionally regulated by CREB1, which is a validated target of miR-296-3p [22]; Tnf and $V d r$ are validated targets of miR298-5p [23,24]. All other targets were computationally 


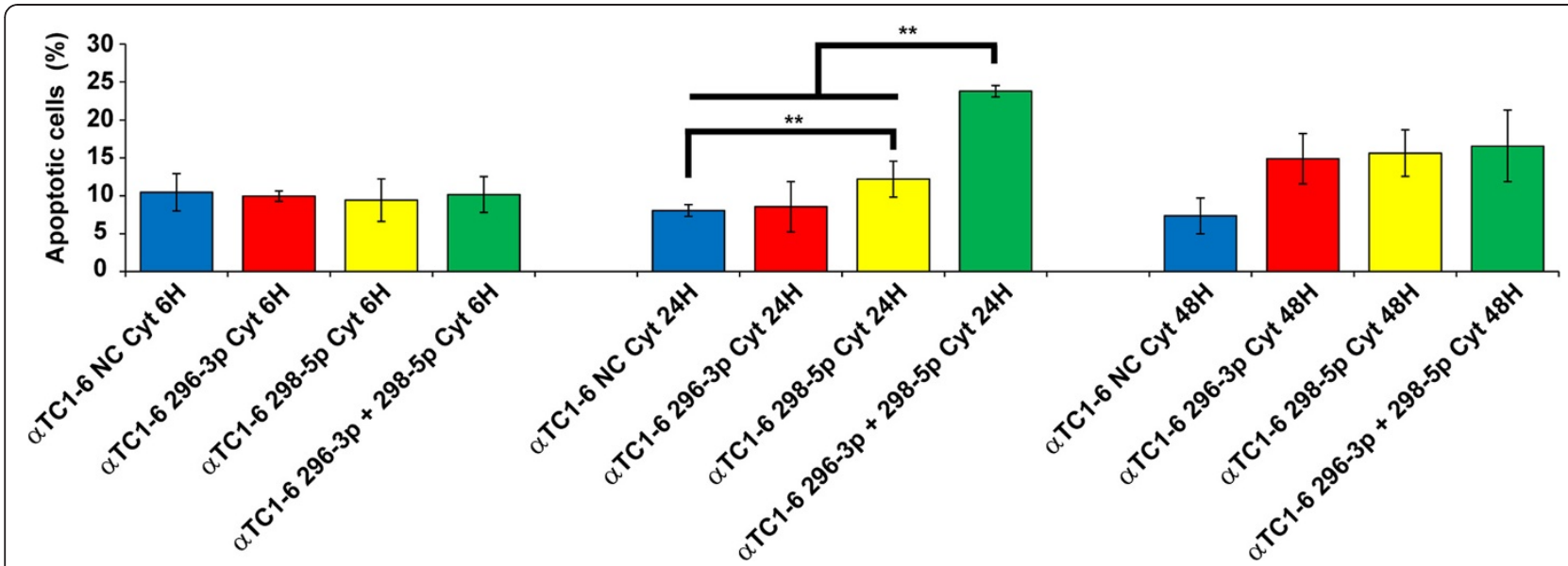

Figure 3 Upregulation of miR-296-3p and miR-298-5p reduces aTC1-6 resistance to apoptosis induced by cytokines. Annexin $V$ flow cytometric analysis of apoptosis in aTC1-6 transiently transfected with scrambled oligonucleotides (NC, Negative Control), mimics of miR-296-3p, miR-298-5p, a mix of both, and treated with IFN- $y, I L-1 \beta$, TNF-a for 6, 24, $48 \mathrm{~h}$. The $y$-axis represents the percentage of apoptotic cells; the $x$-axis represents the four experimental conditions [(i)scramble-transfected cells; (ii) cells transfected with mimics of miR-296-3p; (iii) cells transfected with mimics of miR-298-5p; (iv) cells transfected with a mix of both] assayed at the three time-points. Data are presented as mean \pm S.D. of three independent experiments $(n=3)$. All the possible pairwise comparisons were performed among the four different experimental conditions within each time point: significant differences have been assessed through Tukey HSD post-hoc one-way ANOVA test (** p-value $<0.01$ ). At $24 \mathrm{~h}$ PT, aTC1-6 transfected with mimics of miR-298-5p show a highly significant increase of the number of apoptotic cells with respect to scrambletransfected control; at the same time point, in aTC1-6 transfected with mimics of both miR-296-3p and miR-298-5p a highly significant increase of the number of apoptotic cells is detected with respect to all the other experimental conditions.

predicted, including IGF1R $\beta$ that we validated through western analysis (see later).

\section{Modulation of miR-296-3p and miR-298-5p also alters expression of their targets}

To verify whether in vitro modulation of miR-296-3p and miR-298-5p affected the expression of their targets, we performed transient transfection experiments of aTC1-6 cells with their mimics. Transfection efficiency at $24 \mathrm{~h} \mathrm{AT}$ was in all cases higher than 90\%. In $\alpha \mathrm{TC} 1$ transfected with mimics of miR-296-3p or miR-298-5p, real-time PCR showed altered expression of different genes with respect to scramble-transfected cells, including Igf1r, Tnf, $V d r$ (Figure 4).

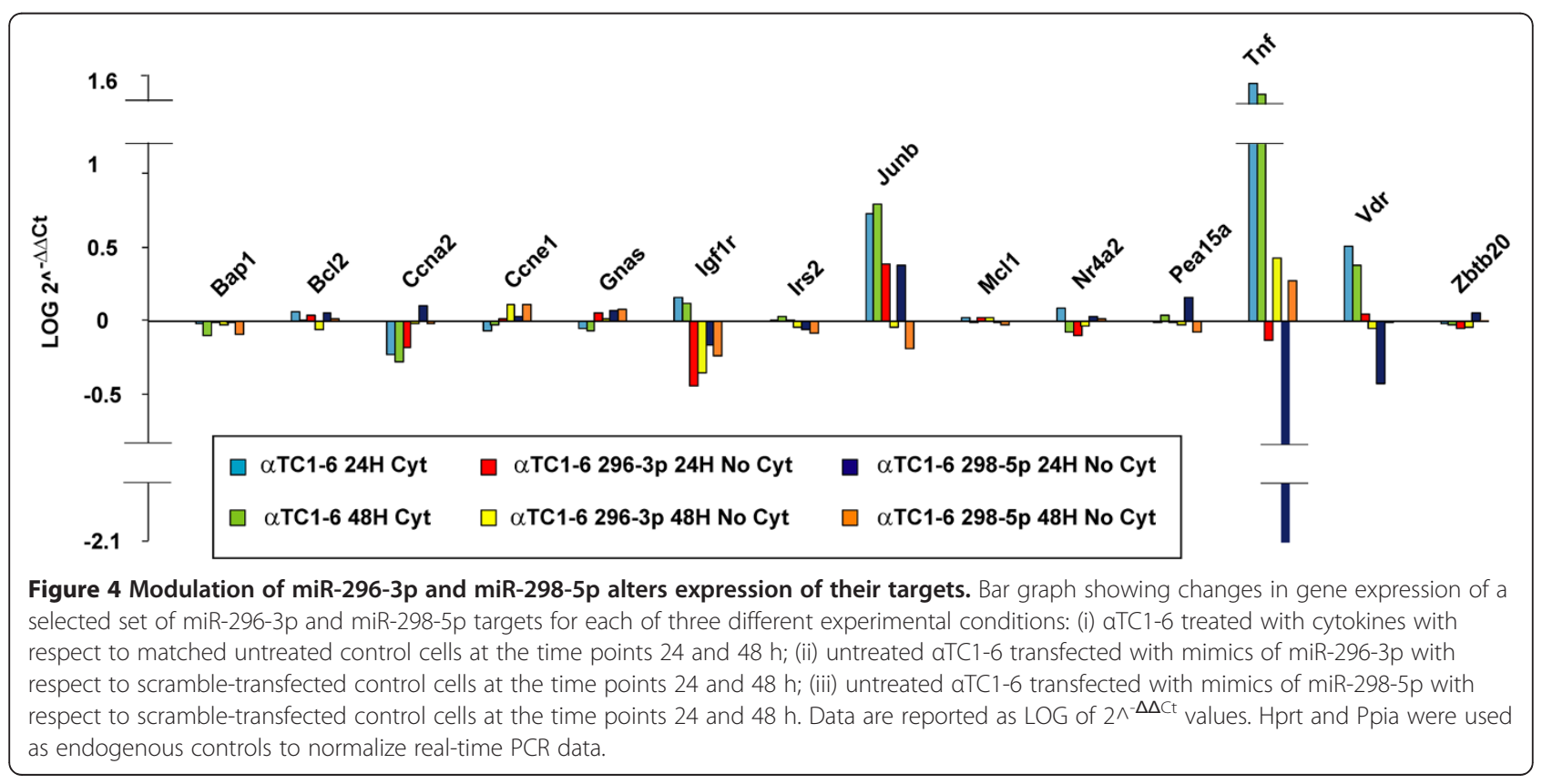


Expression of IGF1R $\beta$ and TNFa is controlled by miR-296$3 p$ and miR-298-5p in aTC1-6 cells

In $\alpha$ TC1-6 treated with cytokines for $24 \mathrm{~h}$, levels of proteins IGF1R $\beta$ and TNF $\alpha$ increased 1.5 and 1.7 folds with respect to untreated controls, respectively (Figures $5 \mathrm{~A}$ and $5 \mathrm{~B}$, right panels), while miRNAs 296-3p and 298-5p decreased of 3.7 and 2.2 folds with respect to untreated controls, respectively (Figure 2B). We further demonstrated through western analysis that protein IGF1R $\beta$ decreased about 1.4 folds in steady-state $\alpha$ TC1- 6 after transfection with mimics of miR-296-3p or miR-298-5p, as compared to scramble-transfected controls; this decrease was higher than 3 folds when cells were transfected with both mimics (Figure 5A, left panel). The decrease of IGF1R $\beta$ was not detectable in $\alpha$ TC1- 6 transfected with either mimic of miR-296-3p or miR-298-5p and then treated with cytokines for $24 \mathrm{~h}$. In $\alpha \mathrm{TC} 1-6$ treated with cytokines for $24 \mathrm{~h}$, after transfection with mimics of both miRNAs 296-3p and 298-5p, it was instead lower than at steady state (1.4 folds). This could also be due to the decrease of miRNAs 296-3p and 298$5 \mathrm{p}$ following treatment with cytokines (Figures 2B and $5 \mathrm{~A}$, middle panel). Following transfection of $\alpha \mathrm{TC} 1-6$ with either mimics of miR-296-3p or miR-298-5p, TNF $\alpha$ protein was about 1.2 folds less expressed with respect to scramble-transfected controls; this decrease was more pronounced (1.6 folds) when cells were transfected with both mimics (Figure 5B, left panel). Each of the two miRNA mimics decreased the expression of TNF $\alpha$ more than 2 folds after $24 \mathrm{~h}$ of treatment with cytokines, but the silencing effect was not potentiated when the two mimics were transfected together (Figure 5B, middle panel).

\section{Activation of IRS-1 and ERK-1 is also under control of miR-296-3p and miR-298-5p}

To verify if the IGF1R signaling pathway was controlled by miR-296-3p and miR-298-5p through IGF1R $\beta$, we assayed the phosphorylation levels of IRS-1 and ERK (two markers downstream the IGF-1 receptor) in $\alpha \mathrm{TC} 1-6$ transfected with mimics of each one or both miRNAs; this analysis was performed both after treatment with cytokines for $24 \mathrm{~h}$ or on untreated cells, exploiting as controls matched scramble-transfected $\alpha$ TC1- 6 cells. The expression of phospho-IRS-1 didn't change in untreated $\alpha$ TC1- 6 transfected with mimics of each miRNA alone, while it decreased about 1.5 folds in $\alpha$ TC1-6 transfected with
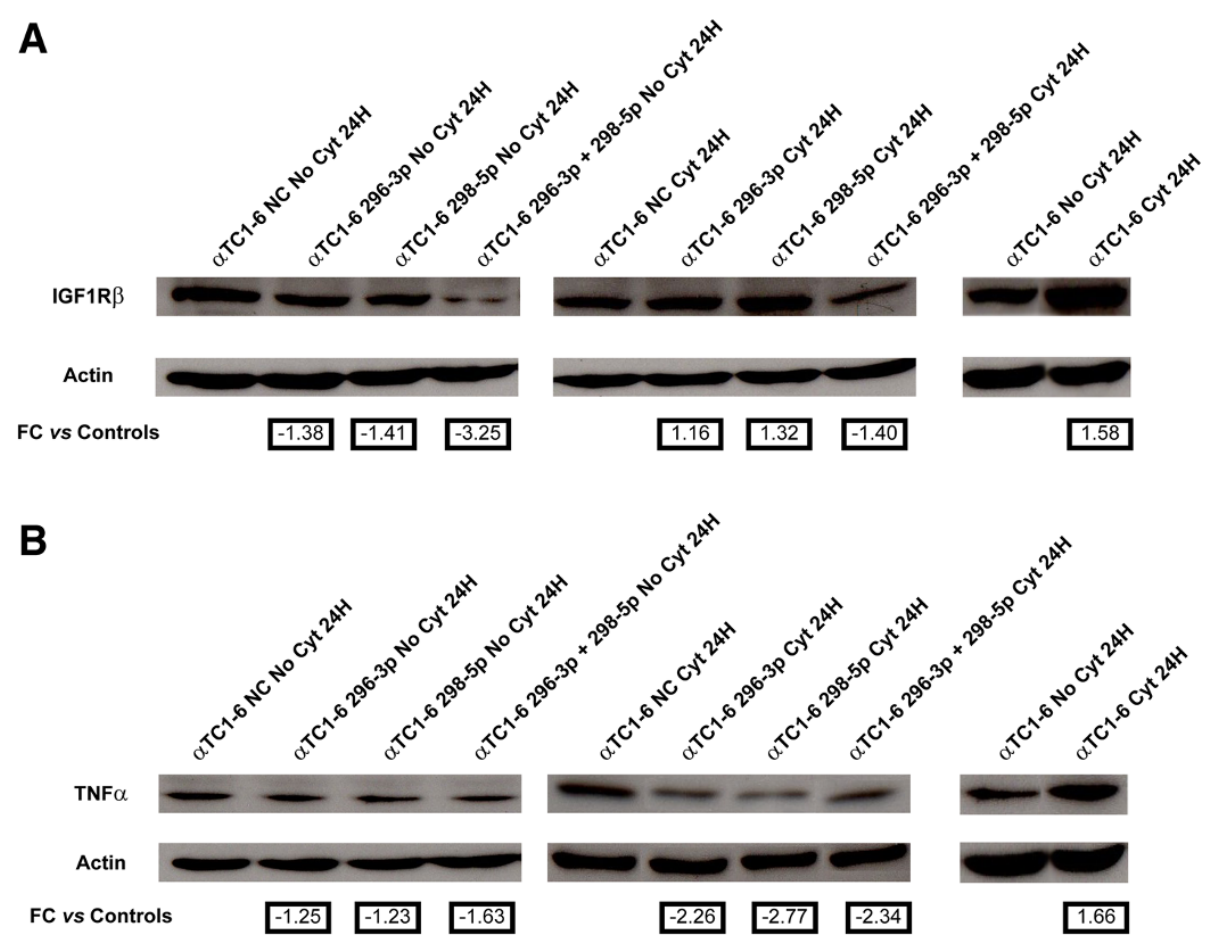

Figure 5 Expression of IGF1R $\beta$ and TNFa proteins is regulated by miR-296-3p and miR-298-5p in aTC1-6. (A) Western analysis of IGF1R $\beta$ in (1) untreated aTC1-6 transfected for $24 \mathrm{~h}$ with (i) scramble molecules (NC); (ii) mimics of miR-296-3p; (iii) mimics of miR-298-5p; (iv) mimics of both miR-296-3p and miR-298-5p (left); (2) aTC1-6 transfected for $24 \mathrm{~h}$ with (i) scramble molecules (NC); (ii) mimics of miR-296-3p; (iii) mimics of miR-298-5p; (iv) mimics of both miR-296-3p and miR-298-5p and treated with cytokines for further $24 \mathrm{~h}$ (middle); (3) aTC1-6 treated with cytokines for $24 \mathrm{~h}$ and their matched untreated controls (right). (B) Western analysis of TNF-a performed in the same experimental conditions as (A). $\beta$-Actin signal was used to normalize the data. Numbers below Actin blots represent fold change expression values relative to matched controls. 
mimics of both miR-296-3p and miR-298-5p (Figure 6A, left panel). By using the same controls, we detected a slight decrease of phospho-IRS-1 (1.2 folds) in $\alpha$ TC1- 6 transfected with mimics of both miR-296-3p and miR298-5p and treated with cytokines (Figure 6A, right panel). Interestingly, also the activation of ERK-1 appears to be regulated by miR-296-3p and miR-298-5p: in the absence of treatment with cytokines, $\alpha \mathrm{TC} 1-6$ cells transfected with mimics of miR-296-3p showed levels of phospho-ERK-1 (Thr202) similar to those found in scramble-transfected aTC1- 6 cells; the transfection with mimics of miR-298-5p or of both miRNAs led instead to a decrease of the protein (1.2 and 1.3 folds, respectively) (Figure 6B, left panel). Under cytokine treatment, the amount of phospho-ERK-1 (Thr202) did not change in $\alpha$ TC1- 6 transfected with either mimics of miR-296-3p or of miR-298-5p alone, compared to scramble-transfected cells; in $\alpha$ TC1-6 simultaneously transfected with mimics of both miRNAs, we detected a decrease of 1.7 folds of phospho-ERK-1 (Thr202) levels, compared to scramble-transfected cells (Figure 6B, right panel).

\section{Identification of TFs regulating DE miRNAs}

In the genomic region comprising the genes encoding miR-296-3p, miR-298-5p and Nespas, MatInspector identified Transcription Factor Binding Sites (TFBS) for sixty seven Transcription Factors (TFs). Four of them (HMX2, HNF4A, LEF1, MAFB) are known to be expressed in the islets of Langerhans, and MAFB is known to be expressed only in rodent islet $\alpha$ cells within adult pancreas [25]; the presence of binding sites for this TF within the promoter of the genes encoding miR-296-3p and miR-298-5p suggests that it may regulate the expression of both miRNAs. Multi Experiment Matrix (MEM) showed a statistically highly significant negative correlation (p-values $<0.0001$, Pearson Correlation test) between Mafb and Igf1r. Interestingly, Microrna.org predicts two binding sites for mmu-miR296-3p and mmu-miR-298-5p on Mafb mRNA 3' UTR.

\section{Differences between aTC1- 6 and $\beta$ TC1 steady state regulatory networks}

14 of 73 miRNAs, more abundantly or exclusively expressed at steady state in $\alpha \mathrm{TC} 1-6$ with respect to $\beta \mathrm{TC} 1$, have validated targets known to be expressed in mammalian pancreatic $\alpha$ cells (see link to T1Dbase in Materials and Methods). By using these data, we generated a network comprised of 560 nodes and 8222 edges (see Additional file 9): from this network, we inferred a subnetwork made of $4 \alpha$-miRNAs for which validated targets have been identified, consisting of 117 nodes and 530 edges (see Additional file 10). In the case of $\beta \mathrm{TC} 1$ cells, we found that 36 of 100 miRNAs more abundantly or exclusively expressed with respect to $\alpha \mathrm{TC} 1-6$ have validated targets known to be expressed in pancreatic $\beta$ cells (see link to T1Dbase): a network of 439 nodes and
2079 edges was generated from them (see Additional file 11). The subnetwork made of $15 \beta$-miRNAs consisted of 107 nodes and 132 edges (see Additional file 12). The enrichment in specific biological processes was calculated in pancreatic $\alpha$ TC1- 6 versus $\beta$ TC1 cells subnetworks (networks made of genes regulated by miRNAs specifically expressed at steady state in $\alpha \mathrm{TC} 1-6$ and $\beta \mathrm{TC} 1$ cells, respectively) (Table 1). Interestingly, in the network of genes regulated by $\alpha$-miRNAs, pancreatic $\alpha$ cell fate commitment is a biological process overrepresented with respect to the network regulated by $\beta$-miRNAs (Hypergeometric test, Benjamini-Hochberg adjusted $\mathrm{p}$-value $<0.05$ ). Within the network of genes regulated by $\alpha$-miRNAs, insulin-like growth factor receptor signaling pathway is a biological process significantly enriched among the genes interacting with targets of miR-296-3p and miR-298-5p, with respect to the genes linked to the targets of the other miRNAs ( $\mathrm{p}$ value $=0.039$, Fisher's exact test).

\section{Discussion}

The data reported in this paper and those from the literature [12] confirm that mammalian pancreatic $\alpha$ cells are more resistant than $\beta$ cells to apoptosis induced by cytokines (Figures $1 \mathrm{~A}$ and $1 \mathrm{~B}$ ). Our results suggest that miR296-3p and miR-298-5p play a pivotal role in determining this trait. Due to DM epidemic spreading [26], its molecular characterization has become an important biological and translational problem in BioMedicine [7]. Our HT and network analyses of miRNA transcriptome in $\alpha$ and $\beta$ cells highlighted very different profiles at steady state (see Table 1 , Additional file 1). Computational analysis of these data allowed us to identify a set of miRNAs, specifically synthesized in pancreatic $\alpha$ cells, which appear to also regulate pancreatic $\alpha$ cell commitment. Specific enrichment of pathways, regulated by $\alpha$-miRNAs within this biological process (Table 1), allowed the identification of miRNAs that could be involved in the acquisition of the trait resistance to cytokines-induced cell death upon pancreatic $\alpha$ cells differentiation. Among them, miR-296-3p and miR-298-5p stood out clearly as potentially critical nodes, responsible for $\alpha$ cells resistance to cytokine-induced cell death. In fact, besides being specifically expressed at steady state in $\alpha$ cells ( $\alpha$ TC1-6), but not in $\beta$ cells ( $\beta$ TC1 or INS-1), both miRNAs were significantly co-expressed and downregulated in $\alpha \mathrm{TC1}-6$ during a time-course treatment with cytokines, compared to matched untreated controls (see Figures 2A and $2 \mathrm{~B}$, Additional file 6). Our subsequent functional assays demonstrated that $\alpha \mathrm{TC} 1-6$ transfected with mimics of miR-296-3p and miR-298-5p became susceptible to apoptosis when treated with the same cocktail of cytokines as compared to $\alpha \mathrm{TC} 1-6$ transfected with scramble molecules. Although its biological effect was potentiated when also miR-296-3p was expressed, our results suggest that the role of miR-298-5p is more important in this process than that 

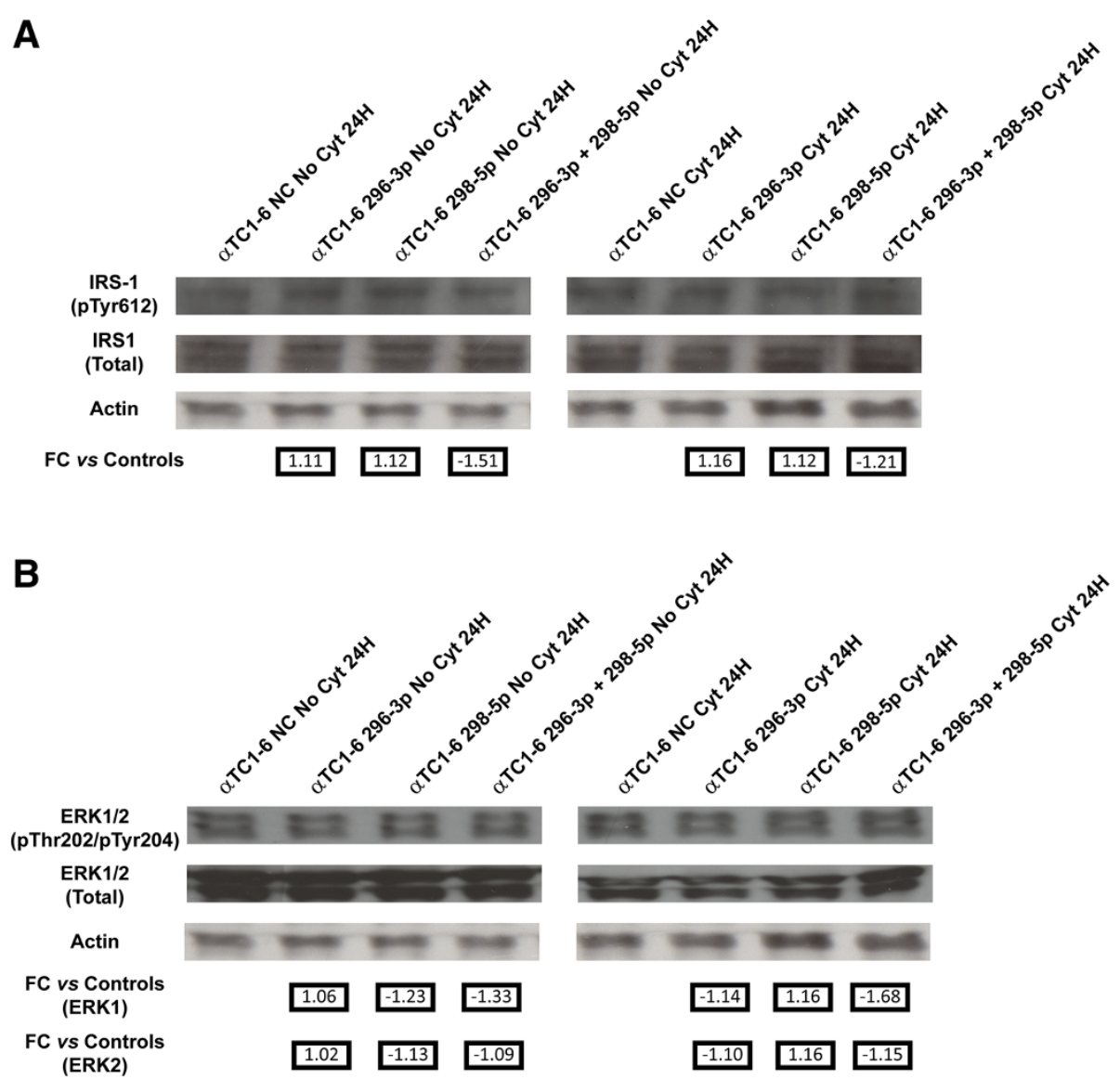

Figure 6 Activation of IRS-1 and ERK-1 is under control of miR-296-3p and miR-298-5p in aTC1-6. (A) Western analysis of phospho-IRS-1 (Tyr612) in (1) untreated aTC1-6 transfected for $24 \mathrm{~h}$ with (i) scramble molecules (NC); (ii) mimics of miR-296-3p; (iii) mimics of miR-298-5p; (iv) mimics of both miR-296-3p and miR-298-5p (left); (2) aTC1-6 transfected for $24 \mathrm{~h}$ with (i) scramble molecules (NC); (ii) mimics of miR-296-3p; (iii) mimics of miR-298-5p; (iv) mimics of both miR-296-3p and miR-298-5p and treated with cytokines for further $24 \mathrm{~h}$ (right). (B) Western analysis of phospho-ERK-1/2 (Thr202/Tyr204) performed in the same experimental conditions as in (A). Quantification of immunoblot signals was made by equalizing phospho-specific IRS-1 or Erk1/2 band intensities to total IRS-1 or Erk1/2, respectively. The decrease in phosphorylation was normalized to the basal level of the control and reported in arbitrary units as fold decrease over basal value. Numbers below Actin blots represent fold change expression values relative to matched controls.

of miR-296-3p (Figure 3): this would highlight the role of one or a few specific miR-298-5p targets. Through western analysis, we confirmed our computational prediction that IGF1R $\beta$ and TNF $\alpha$ are common targets to both miRNAs and that miR-296-3p and miR-298-5p also control IRS-1

Table 1 Top 5 biological processes significantly enriched in a-miRNA networks with respect to $\beta$-miRNA networks

\begin{tabular}{cc}
\hline Biological process & $\begin{array}{c}\text { Adj-p-value } \\
\text { (Benjamini-Hochberg) }\end{array}$ \\
\hline DNA replication & $3.15 \mathrm{E}-23$ \\
\hline Cell division & $2.51 \mathrm{E}-09$ \\
\hline Cellular response to metal ion & $4.61 \mathrm{E}-05$ \\
\hline $\begin{array}{c}\text { Positive regulation of mesenchymal cell } \\
\text { proliferation }\end{array}$ & $5.24 \mathrm{E}-05$ \\
\hline \multicolumn{2}{c}{ Pancreatic a cell fate commitment } \\
\hline
\end{tabular}

Biological processes are ranked based on increasing adjusted $p$-values (from the most to the least significant biological process). and ERK-1 within the IGF1R signaling pathway. IGF1R is known to promote resistance to apoptosis by different mechanisms: it increases the levels of antiapoptotic proteins, as BCL2 and BCL-XL; it inactivates proapoptotic proteins, as BAD and CASP9; it stimulates mitogenic IRS-1/ MAPKs pathway [27-29]. Phospho-IRS1 (Tyr612) and Phospho-ERK-1 (Thr202), which we demonstrated to be controlled by miR-296-3p and miR-298-5p, are known to regulate the response to insulin and to be involved in survival and proliferation processes [30]. Decreased expression of mir-296-3p and miR-298-5p and the corresponding activation of survival and proliferation signals, mediated by IGF1R and its downstream nodes (e.g., IRS-1 and ERK-1), may thus explain why $\alpha$ TC1- 6 cells are resistant to death induction by cytokines (see Additional file 13). TNF $\alpha$ is known to be physiologically expressed by pancreatic endocrine cells and to contribute to maintain islet homeostasis [5,31]. This protein is also known to decrease apoptosis levels 
of pancreatic acinar cells during acute pancreatitis by stimulating the synthesis of antiapoptotic proteins [32].

\section{Conclusions}

HT miRNA profiling data, functional analysis with synthetic mimics and molecular characterisation of modulated pathways strongly suggest that specific downregulation of miR-296-3p and miR-298-5p in pancreatic $\alpha$ cells, coupled to upregulation of their targets as IGF1R $\beta$ and TNF $\alpha$ and activation of the corresponding signaling pathways, is a major determinant of their resistance to apoptosis induction by cytokines. Studies on pancreatic islet microorgan in toto will allow to experimentally confirm these results in a $3 \mathrm{D}$ natural system. It also will permit to verify the hypothesis that increased TNF $\alpha$ synthesis by $\alpha$ cells during insulitis protects them by activating survival pathways, while priming a deadly regulatory loop and causing $\beta$ cells apoptosis (see Additional file 13).

\section{Methods}

\section{Cell culture and treatment with cytokines}

Mouse glucagonoma cell line $\alpha$ TC1- 6 was obtained from the American Type Culture Collection (ATCC); it was cultured in complete Dulbecco's modified Eagle's medium (DMEM, Sigma-Aldrich $^{\circledR}$, Saint Louis, MO, USA), as described [33]. Mouse insulinoma cell line $\beta$ TC1 also was from ATCC; cells were grown in DMEM with $25 \mathrm{mM}$ glucose (SigmaAldrich $^{\circledR}$ ), supplemented with $2 \mathrm{mM}$ L-Glutamine, $15 \%$ heat inactivated (HI) horse serum, 2.5\% HI fetal bovine serum (FBS), 1\% penicillin/streptomycin, in 95\% humidified air-5\% $\mathrm{CO}_{2}$ at $37^{\circ} \mathrm{C}$. Cells were passaged once a week after trypsinization and replaced with new medium twice weekly. Treatment with cytokines (recombinant murine IL-1 $\beta$, specific activity $5 \times 10^{8} \mathrm{U} / \mathrm{mg}$, Preprotech, London, UK, UE; recombinant murine IFN- $\gamma$, specific activity $1 \times 10^{7} \mathrm{U} / \mathrm{mg}$, Preprotech; recombinant murine TNF- $\alpha$, specific activity $1 \times 10^{7}$ U/mg, Preprotech) was as described [34]. $\alpha$ TC1-6 cells (passages 20-40) were seeded the day before treatment in 60 $\mathrm{mm}$ dishes at a density of $4.5 \times 10^{5}$ cells.

\section{Evaluation of apoptosis and necrosis}

Percentage of apoptotic or necrotic cells was assessed through flow cytometry. Analysis was performed with a Beckman Coulter Epics XL-MCL flow cytometer (Beckman Coulter $^{\odot}$, Inc., Hialeah, FL, USA). Cells were collected, washed with phosphate-buffered saline (PBS), and stained with Annexin V-FITC/propidium iodide (PI) (SigmaAldrich $^{\circledR}$ ) in Annexin-V binding buffer, as specified by the manufacturer. EXPO32 ADC Analysis ${ }^{\mathrm{TM}}$ software package (Beckman Coulter ${ }^{\odot}$, Inc.) was used for data analysis.

\section{RNA extraction and HT quantitative RT-PCR}

Total RNA was extracted with Trizol (Lifetechnologies ${ }^{\mathrm{TM}}$, Foster-City, CA, USA), according to manufacturer's instructions. RNA quantification was performed with a Qubit $^{\circledR}$ Fluorometer (Lifetechnologies ${ }^{\mathrm{TM}}$ ). RNA for HT miRNA expression profiling was reverse transcribed into cDNA of 519 mouse-specific and 68 rat-specific miRNAs through Megaplex ${ }^{\mathrm{TM}}$ RT Rodent Primer Pool sets, and preamplified through Megaplex ${ }^{\mathrm{TM}}$ PreAmp Rodent Primer Pool sets (Lifetechnologies ${ }^{\mathrm{TM}}$ ). Resulting cDNAs were loaded onto TaqMan Low Density miRNA Arrays (TLDA) cards, according to manufacturer's instructions. TLDA cards were run on ABI 7900HT Real Time PCR system. RNA for Single TaqMan miRNA Assays was reverse transcribed into miRNA-specific cDNA through TaqMan ${ }^{\circledR}$ MicroRNA Reverse Transcription Kit (Lifetechnologies ${ }^{\mathrm{TM}}$ ) and amplified using TaqMan ${ }^{\circledR}$ Universal Master Mix (Lifetechnologies ${ }^{\mathrm{TM}}$ ), according to manufacturer's instruction. RNA for analysis of miRNA targets was reverse transcribed into cDNA through High Capacity RNA-to-cDNA Kit (Lifetechnologies ${ }^{\mathrm{TM}}$ ) and amplified through Fast SYBR ${ }^{\circledR}$ Green Master Mix (Lifetechnologies ${ }^{\mathrm{TM}}$ ), according to manufacturer's instruction. Primer sequences are available upon request.

\section{Criteria for selecting downregulated or overexpressed miRNAs}

Data quality and quantification were computed using Real-Time Statminer ${ }^{\circledR}$ software (www.integromics.com) (Integromics, Granada, Spain). Multiple reference genes were used to normalize data: Genorm (integrated into RealTime Statminer ${ }^{\circledR}$ ) [35] and DataAssist ${ }^{\text {TM }}$ (Lifetechnologies $^{\mathrm{TM}}$ ) softwares allowed to choose the best ones. Limma test (see below: Statistical analysis) was carried out by Real-Time Statminer ${ }^{\circledR}$ to assess statistically significant DE genes. DE miRNAs were ranked based on their $\mathrm{p}$-values and adjusted p-values (Benjamini-Hochberg correction with False Discovery Rate, FDR, set at 5\%). Relative quantities (RQ) of miRNAs between $\alpha \mathrm{TC} 1-6$ and $\beta \mathrm{TC} 1$, at steady state as between treated $\alpha \mathrm{TC} 1-6$ cells and matched untreated controls, were calculated according to $2^{-\Delta \Delta \mathrm{Ct}}$ method [36]. Values are reported as average fold changes of three independent biological replicates; RQ values $<1$ were converted to negative fold changes by the formula: $-1 / R Q$. The data files for each array are publicly available at the Gene Expression Omnibus (GEO) database repository (http://www.ncbi.nlm.nih.gov/geo/) (GSE42970).

Transient transfection of aTC1-6 cells with mimics of miR296-3p and miR-298-5p

For transfection, $\alpha \mathrm{TC} 1-6$ cells were plated into 24-well plates at a density of $4 \times 10^{4}$ cells per well to obtain RNA, and into $100 \mathrm{~mm}$ dishes at a density of $1.15 \times 10^{6}$ cells to obtain proteins. Transfections were performed using siPORT $^{\mathrm{TM}}$ NeoFX $^{\mathrm{TM}}$ (Lifetechnologies ${ }^{\mathrm{TM}}$ ) with $30 \mathrm{nM}$ mimics of miR-296-3p/miR-298-5p/scrambled sequence (Pre$\mathrm{miR}^{\mathrm{TM}}$ miRNA Precursor Molecules-Negative Control \#1, 
Lifetechnologies $^{\mathrm{TM}}$ ). For each experiment, efficiency of transfection was measured through real-time PCR.

\section{In silico identification of miRNA targets}

Validated targets of DE miRNAs were retrieved from the literature and miRTarbase (release 2.5) [37]. Predictions were performed through starBase (release 2.1) (http:// starbase.sysu.edu.cn/). Among validated and predicted targets, only genes expressed in pancreatic cells (data from Beta Cell Gene Atlas, found at http://t1dbase.org/ page/AtlasHome) and known to be functionally involved in cell survival or death were chosen for real-time PCR and western blot assays. Data on genomic position of genes encoding miRNAs and their assignment to specific families were from MiRBase (http://www.mirbase.org/).

\section{Western analysis}

Protein lysates and their quantification were obtained as previously described [38]. $50 \mu \mathrm{g}$ of total protein extract were loaded into $10 \%$ SDS polyacrylamide gel (Hoefer miniVE, GE Healthcare ${ }^{\odot}$, Amersham Place, Buckinghamshire, UK) and blotted to nitrocellulose membranes by iBlot Dry Blotting System (Lifetechnologies ${ }^{\mathrm{TM}}$ ). Membranes were probed with polyclonal antibodies to IGF1R $\beta$ (Santa Cruz Biotechnology ${ }^{\circledR}$, Inc., Dallas, TX, USA), p-IRS-1 (Santa Cruz Biotechnology ${ }^{\circledR}$, Inc.), total-IRS-1 (EMD Millipore Corporation $^{\odot}$, Billerica, MA, USA), p-p44/p42 MAPK (Cell Signaling Technology ${ }^{\circledR}$, Inc., Danvers, MA, USA), total p44/p42 MAPK (Cell Signaling Technology ${ }^{\circledR}$, Inc.), TNF $\alpha$ (Cell Signaling Technology ${ }^{\circledR}$, Inc.), using $\beta$-actin (SigmaAldrich $^{\circledR}$ ) as loading control. Proteins were detected by using $\mathrm{ECL}^{\mathrm{TM}}$ Western Blotting Detection Reagents (GE Healthcare $\left.^{(}\right)$. Densitometric analyses were performed by ImageJ software (http://rsbweb.nih.gov/ij/index.html)

\section{Prediction of transcription factors regulating expression of miRNAs 296-3p and 298-5p}

MatInspector from Genomatix (http://www.genomatix. de/) was used to identify Transcription Factors Binding Sites (TFBS) and their corresponding Transcription Factors (TFs) [39]. By using Multi Experiment Matrix (MEM) (http://biit.cs.ut.ee/mem) (selected collection: Affymetrix GeneChip Mouse Genome 4302.0 [Mouse_430_2] platform, used to analyze 1546 datasets), TFs prediction was interpolated with data on statistically significant expression correlation among TFs, which regulate DE miRNAs and their mRNA targets. Settings used in MEM are described in Additional file 14.

\section{Identification of CpG islands upstream the genes} encoding Nespas, miR 296-3p and miR 298-5p

CpG islands upstream genes encoding miR-296, miR-298, Nespas were identified through UCSC Genome Browser (http://genome.ucsc.edu/).

\section{Network analysis}

Biological networks comprising miRNAs, their predicted upstream regulators (TFs), their validated targets and first neighbours interactants, were generated by retrieving interactome data through MiMI Cytoscape plugin [40] and visualized by Cytoscape v. 2.8.1. Biological processes and pathways involving network nodes were analyzed through the tool DAVID (http://david.abcc.ncifcrf. gov/) and BiNGO Cytoscape plugin [41]

\section{Statistical analysis}

P-values were calculated by applying different methods: Limma test [42], associated with Benjamini-Hochberg correction for multiple comparison, was applied to identify DE miRNA genes between test and control samples in HT miRNA transcriptome analyses; Student's $t$-test, associated with Bonferroni correction method, was used to statistically analyze data from single TaqMan assays and to assess significantly different apoptotic levels between $\alpha \mathrm{TC} 1-6$ treated with cytokines and their matched untreated controls; Tukey HSD post-hoc one-way ANOVA test was used to evaluate significant differences in apoptosis among different transfection experimental conditions. For analysis of correlation between the expression of miR-296-3p and miR-298-5p in aTC1-6, Pearson correlation coefficient was calculated. Finally, $x^{2}$-square test was used to establish if miR-296-3p and miR-298-5p have more common targets than expected by chance; Fisher's exact test was applied to evaluate the enrichment in specific gene ontologies. All statistical tests and correction methods, used to calculate p-values, are described throughout the text and figure legends.

\section{Nomenclature of genes and proteins}

Rules for official gene and protein symbols by the International Committee on Standardized Genetic Nomenclature for Mice were followed throughout [43] (http:// www.informatics.jax.org/mgihome/nomen/gene.shtml).

\section{Additional files}

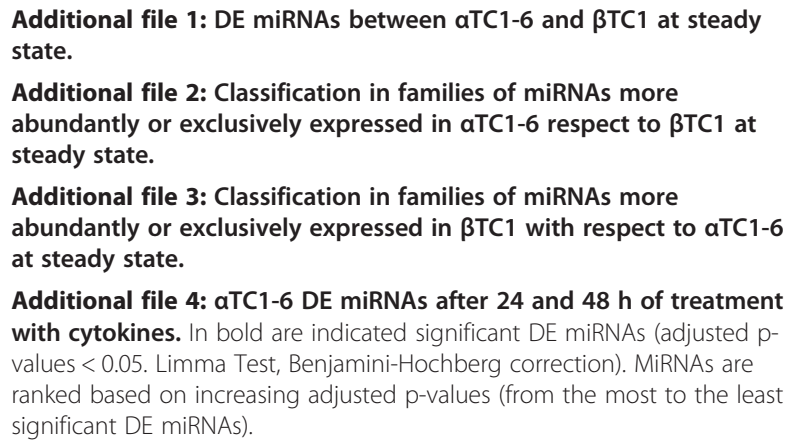

Additional file 4: aTC1-6 DE miRNAs after 24 and $48 \mathrm{~h}$ of treatment with cytokines. In bold are indicated significant DE miRNAs (adjusted pvalues < 0.05. Limma Test, Benjamini-Hochberg correction). MiRNAs are ranked based on increasing adjusted p-values (from the most to the least significant DE miRNAs).

Additional file 5: Classification in families of DE miRNAs in aTC1-6 after treatment with cytokines. 
Additional file 6: Scatter plot showing correlation between miR296-3p ( $x$-axis) and miR-298-5p (y-axis) expression in aTC1-6, during a 6-12-24-48 $\mathrm{h}$ time-course experiment. For each time point DCt values of miR-296-3p and miR-298-5p were correlated, both from untreated and cytokines-treated aTC1- 6 cells ( $r$-value $=0.88$, p-value $=$ 1.15e-08, Pearson's correlation test). Three independent biological replicates $(n=3)$ have been analyzed at each time point.

Additional file 7: On scale representation of the genome segment comprising Nespas, miR-296, miR-298. CpG islands are indicated as red vertical lines; pre-miRNAs 296 and 298 are depicted as blue and green boxes, respectively; exons of noncoding RNA Nespas are shown as yellow boxes. Expression of a macro-noncoding RNA (precursor of miR296, miR-298, Nespas) is predicted to be controlled by two groups of CpG islands (one comprising two CpG islands, from 17.5 to $18.8 \mathrm{~kb}$ upstream the first nucleotide of pre-miR-296; the other made of three CpG islands, from 30.1 to $33.6 \mathrm{~Kb}$ upstream the first nucleotide of pre-miR-296).

Additional file 8: Validated and predicted targets of miR-296-3p and miR-298-5p. A selection of validated and predicted targets of miR296-3p and miR-298-5p was chosen according to their involvement in apoptosis, cell cycle progression, cell differentiation and hormone secretion.

Additional file 9: Interaction network among miRNAs more abundantly expressed at steady state in aTC1-6 with respect to $\beta \mathrm{TC1}$, their validated targets and first neighbours interactants. The network generated from validated targets and first neighbours interactants of 14 out of 50 miRNAs, more abundantly expressed at steady state in aTC1-6 with respect to $\beta$ TC1, consisted of 560 nodes and 8222 edges. MiRNAs are represented as fuchsia diamonds. This file can be opened and browsed through Cytoscape tool and its plugins (http:// www.cytoscape.org/).

Additional file 10: Interaction network among miRNAs specifically expressed at steady state in aTC1-6 (a-miRNAs) with respect to $\beta T C 1$, their validated targets and first neighbours interactants. The network generated from validated targets and first neighbours interactants of 4 out of 23 a-miRNAs consisted of 117 nodes and 530 edges. MiRNAs are represented as fuchsia diamonds. This file can be opened and browsed through Cytoscape tool and its plugins (http:// www.cytoscape.org/).

Additional file 11: Interaction network among miRNAs more abundantly expressed at steady state in $\beta \mathrm{TC} 1$ with respect to aTC1-6, their validated targets and first neighbours interactants. The network generated from validated targets and first neighbours interactants of 36 of 74 miRNAs more abundantly expressed at steady state in BTC1 with respect to aTC1-6 consisted of 439 nodes and 2079 edges. MiRNAs are represented as fuchsia diamonds. This file can be opened and browsed through Cytoscape tool and its plugins (http:// www.cytoscape.org/).

Additional file 12: Interaction network among miRNAs specifically expressed at steady state in $\beta$ TC1-6 ( $\beta$-miRNAs) with respect to aTC1-6, their validated targets and first neighbours interactants. The network generated from validated targets and first neighbours interactants of 15 of $26 \beta$-miRNAs consisted of 107 nodes and 132 edges. MiRNAs are represented as fuchsia diamonds. This file can be opened and browsed through Cytoscape tool and its plugins (http://www. cytoscape.org/).

Additional file 13: Hypothetical model of regulation of miR-296-3p and miR-298-5p biomolecular activity in aTC1-6 at steady state (left) and after treatment with cytokines (right).

Additional file 14: Additional Methods.

\section{Abbreviations}

AT: After transfection; DE: Differentially expressed; DM: Diabetes mellitus; GLP1: Glucagon-like peptide 1; HT: High-throughput; IFN- - : Intereferon gamma; IL-1 $\beta$ : Interleukin 1 beta; miRNA: microRNA; Ngn3: Neurogenin 3; PT: Post treatment; STAs: Single TaqMan gene expression assays; T1DM: Type 1 diabetes mellitus; T2DM: Type 2 diabetes mellitus; TLDA: TaqMan Low Density Array; TNF-a: Tumor Necrosis Factor alpha; TSS: Transcription Start Site.

\section{Competing interests}

The authors declare that they have no competing interests.

\section{Authors' contributions}

MP and FP conceived and coordinated the project; MP, FP, DB, SP, AMR, CDP designed experiments, DB, AGC, LGM, FU, NP, AM, LS performed them; MP, FP, DB wrote the paper; all authors contributed to the critical revision of the data, read and approved the final manuscript.

\section{Acknowledgements}

This project was supported by funds from Ministero dell'Università e della Ricerca Scientifica e Tecnologica to Prof. M. Purrello and Prof. F. Purrello. We thank the Reviewers for their constructive and insightful comments, which helped us to improve the paper. We acknowledge the assignment to Dr. D. Barbagallo of the Accademia Gioenia (Catania) prize for the best PhD thesis in the field of Molecular Biology of Complex Systems (years 2009-2011). We thank Dr. S Fanti (BIOGENERICA s.r.I.) and Dr. P Scacciante (CO.DI.SAN SPA) for their kind cooperation. We acknowledge the technical collaboration of Mr. A Vasta.

\section{Author details}

'Dipartimento Gian Filippo Ingrassia, Unità di BioMedicina Molecolare Genomica e dei Sistemi Complessi, Genetica, Biologia Computazionale, Università di Catania, Catania, EU 95123, Italy. ${ }^{2}$ Dipartimento di BioMedicina Clinica e Molecolare, Università di Catania, Catania, EU 95122, Italy.

Received: 16 October 2012 Accepted: 26 January 2013 Published: 29 January 2013

\section{References}

1. Thomas HE, Graham KL, Chee J, Thomas R, Kay TW, Krishnamurthy B: Proinflammatory cytokines contribute to development and function of regulatory T cells in type 1 diabetes. Ann N Y Acad Sci, in press.

2. Cruz NG, Sousa LP, Sousa MO, Pietrani NT, Fernandes AP, Gomes KB: The linkage between inflammation and Type 2 diabetes mellitus. Diabetes Res Clin Pract, in press.

3. Butler AE, Janson J, Bonner-Weir S, Ritzel R, Rizza RA, Butler PC: Beta-cell deficit and increased beta-cell apoptosis in humans with type 2 diabetes. Diabetes 2003, 52:102-110.

4. Deng S, Vatamaniuk M, Huang X, Doliba N, Lian MM, Frank A, Velidedeoglu E, Desai NM, Koeberlein B, Wolf B, Barker CF, Naji A, Matschinsky FM, Markmann JF: Structural and functional abnormalities in the islets isolated from type 2 diabetic subjects. Diabetes 2004, 53:624-632.

5. Donath MY, Størling J, Berchtold LA, Billestrup N, Mandrup-Poulsen T: Cytokines and beta-cell biology: from concept to clinical translation. Endocr Rev 2008, 29:334-350.

6. Bramswig NC, Kaestner KH: Transcriptional regulation of a-cell differentiation. Diabetes Obes Metab 2011, 13(Suppl 1):13-20.

7. Unger RH, Cherrington AD: Glucagonocentric restructuring of diabetes: a pathophysiologic and therapeutic makeover. J Clin Invest 2012, 122:4-12.

8. Grunnet LG, Aikin R, Tonnesen MF, Paraskevas S, Blaabjerg L, Størling J, Rosenberg L, Billestrup N, Maysinger D, Mandrup-Poulsen T: Proinflammatory cytokines activate the intrinsic apoptotic pathway in beta-cells. Diabetes 2009, 58:1807-1815.

9. Cnop M, Welsh N, Jonas JC, Jörns A, Lenzen S, Eizirik DL: Mechanisms of pancreatic beta-cell death in type 1 and type 2 diabetes: many differences, few similarities. Diabetes 2005, 54(Suppl 2):97-107.

10. Ellingsgaard $H$, Ehses JA, Hammar EB, Van Lommel L, Quintens R, Martens $G$, Kerr-Conte J, Pattou F, Berney T, Pipeleers D, Halban PA, Schuit FC, Donath MY: Interleukin-6 regulates pancreatic alpha-cell mass expansion. Proc Natl Acad Sci USA 2008, 105:13163-13168

11. Hamaguchi K, Leiter EH: Comparison of cytokine effects on mouse pancreatic alpha-cell and beta-cell lines. Viability, secretory function, and MHC antigen expression. Diabetes 1990, 39:415-425.

12. Iwahashi $\mathrm{H}$, Hanafusa T, Equchi Y, Nakajima H, Miyagawa J, Itoh N, Tomita K Namba M, Kuwajima M, Noguchi T, Tsujimoto Y, Matsuzawa Y: Cytokine-induced apoptotic cell death in a mouse pancreatic beta-cell line: inhibition by Bcl-2. Diabetologia 1996, 39:530-536.

13. Takeda Y, Fujita Y, Honjo J, Yanagimachi T, Sakagami H, Takiyama Y, Makino Y, Abiko A, Kieffer TJ, Haneda M: Reduction of both beta cell death and alpha 
cell proliferation by dipeptidyl peptidase- 4 inhibition in a streptozotocininduced model of diabetes in mice. Diabetologia 2012, 55:404-412.

14. Xie T, Chen M, Weinstein LS: Pancreas-specific Gsalpha deficiency has divergent effects on pancreatic alpha- and beta-cell proliferation. J Endocrinol 2010, 206:261-269

15. Bartel DP: MicroRNAs: genomics, biogenesis, mechanism, and function. Cell 2004, 116:281-297.

16. Janga SC, Vallabhaneni S: MicroRNAs as post-transcriptional machines and their interplay with cellular networks. Adv Exp Med Biol 2011, 722:59-74.

17. Poy MN, Eliasson L, Krutzfeldt J, Kuwajima S, Ma X, Macdonald PE, Pfeffer S, Tuschl T, Rajewsky N, Rorsman P, Stoffel M: A pancreatic islet-specific microRNA regulates insulin secretion. Nature 2004, 432:226-230.

18. Roggli E, Britan A, Gattesco S, Lin-Marq N, Abderrahmani A, Meda P, Regazzi R: Involvement of microRNAs in the cytotoxic effects exerted by proinflammatory cytokines on pancreatic beta-cells. Diabetes 2010, 59:978-986

19. Zhao X, Mohan R, Özcan S, Tang X: MicroRNA-30d induces insulin transcription factor MafA and insulin production by targeting mitogenactivated protein 4 kinase 4 (MAP4K4) in pancreatic $\beta$ cells. J Biol Chem 2012, 287:31155-31164.

20. Zampetaki A, Kiechl S, Drozdov I, Willeit P, Mayr U, Prokopi M, Mayr A Weger S, Oberhollenzer F, Bonora E, Shah A, Willeit J, Mayr M: Plasma microRNA profiling reveals loss of endothelial miR-126 and other microRNAs in type 2 diabetes. Circ Res 2010, 107:810-817.

21. Robson JE, Eaton SA, Underhill P, Williams D, Peters J: MicroRNAs 296 and 298 are imprinted and part of the GNAS/Gnas cluster and miR-296 targets IKBKE and Tmed9. RNA 2012, 18:135-144.

22. Leone V, D'Angelo D, Ferraro A, Pallante P, Rubio I, Santoro M, Croce CM, Fusco A: A TSH-CREB1-microRNA loop is required for thyroid cell growth. Mol Endocrinol 2011, 25:1819-1830.

23. Mor E, Cabilly Y, Goldshmit Y, Zalts H, Modai S, Edry L, Elroy-Stein O, Shomron N: Species-specific microRNA roles elucidated following astrocyte activation. Nucleic Acids Res 2011, 39:3710-3723.

24. Pan YZ, Gao W, Yu AM: MicroRNAs regulate CYP3A4 expression via direct and indirect targeting. Drug Metab Dispos 2009, 37:2112-2117.

25. Artner I, Le Lay J, Hang Y, Elghazi L, Schisler JC, Henderson E, Sosa-Pineda B, Stein R: MafB: an activator of the glucagon gene expressed in developing islet alpha- and beta-cells. Diabetes 2006, 55:297-304.

26. Lam DW, LeRoith D: The worldwide diabetes epidemic. Curr Opin Endocrinol Diabetes Obes 2012, 19:93-96.

27. Bai HZ, Pollman MJ, Inishi Y, Gibbons GH: Regulation of vascular smooth muscle cell apoptosis. Modulation of bad by a phosphatidylinositol 3-kinase-dependent pathway. Circ Res 1999, 85:229-237.

28. Chrysis D, Calikoglu AS, Ye P, D'Ercole AJ: Insulin-like growth factor-I overexpression attenuates cerebellar apoptosis by altering the expression of $\mathrm{BCl}$ family proteins in a developmentally specific manner. J Neurosci 2001, 21:1481-1489.

29. Vincent AM, Feldman EL: Control of cell survival by IGF signaling pathways. Growth Horm IGF Res 2002, 12:193-197.

30. White MF: IRS proteins and the common path to diabetes. Am J Physiol Endocrinol Metab 2002, 283:E413-422.

31. Lawrence MC, Naziruddin B, Levy MF, Jackson A, McGlynn K: Calcineurin/ nuclear factor of activated T cells and MAPK signaling induce TNF-\{alpha\} gene expression in pancreatic islet endocrine cells. J Biol Chem 2011, 286:1025-1036.

32. Malka D, Vasseur S, Bödeker H, Ortiz EM, Dusetti NJ, Verrando P, Dagorn JC, lovanna JL: Tumor necrosis factor alpha triggers antiapoptotic mechanisms in rat pancreatic cells through pancreatitis-associated protein I activation. Gastroenterology 2000, 119:816-828.

33. Piro S, Maniscalchi ET, Monello A, Pandini G, Mascali LG, Rabuazzo AM, Purrello F: Palmitate affects insulin receptor phosphorylation and intracellular insulin signal in a pancreatic alpha-cell line. Endocrinology 2010, 151:4197-4206.

34. Riboulet-Chavey A, Diraison F, Siew LK, Wong FS, Rutter GA: Inhibition of AMP-activated protein kinase protects pancreatic beta-cells from cytokine-mediated apoptosis and CD8+ T-cell-induced cytotoxicity. Diabetes 2008, 57:415-423.

35. Vandesompele J, De Preter K, Pattyn F, Poppe B, Van Roy N, De Paepe A, Speleman F: Accurate normalization of real-time quantitative RT-PCR data by geometric averaging of multiple internal control genes. Genome Biol 2002, 3:RESEARCH0034.
36. Livak KJ, Schmittgen TD: Analysis of relative gene expression data using real-time quantitative $P C R$ and the 2 (-delta delta $C(T)$ ) method. Methods 2011, 25:402-408.

37. Hsu SD, Lin FM, Wu WY, Liang C, Huang WC, Chan WL, Tsai WT, Chen GZ, Lee CJ, Chiu CM, Chien CH, Wu MC, Huang CY, Tsou AP, Huang HD: miRTarBase: a database curates experimentally validated microRNAtarget interactions. Nucleic Acids Res 2011, 39(Database issue):D163-169.

38. Ragusa M, Statello L, Maugeri M, Majorana A, Barbagallo D, Salito L, Sammito M, Santonocito M, Angelica R, Cavallaro A, Scalia M, Caltabiano R, Privitera G, Biondi A, Di Vita M, Cappellani A, Vasquez E, Lanzafame S, Tendi E, Celeste S, Di Pietro C, Basile F, Purrello M: Specific alterations of the microRNA transcriptome and global network structure in colorectal cancer after treatment with MAPK/ERK inhibitors. J Mol Med (Berl) 2012, 90:1421-1438.

39. Cartharius K, Frech K, Grote K, Klocke B, Haltmeier M, Klingenhoff A, Frisch M, Bayerlein M, Werner T: Matlnspector and beyond: promoter analysis based on transcription factor binding sites. Bioinformatics 2005, 21:2933-2942.

40. Gao J, Ade AS, Tarcea VG, Weymouth TE, Mirel BR, Jagadish HV, States DJ: Integrating and annotating the interactome using the MiMl plugin for cytoscape. Bioinformatics 2009, 25:137-138.

41. Maere S, Heymans K, Kuiper M: BiNGO: a Cytoscape plugin to assess overrepresentation of gene ontology categories in biological networks. Bioinformatics 2005, 21:3448-3449.

42. Smyth GK: Linear models and empirical bayes methods for assessing differential expression in microarray experiments. Stat Appl Genet Mol Biol 2004, 3:Article3.

43. Eppig JT, Blake JA, Bult CJ, Kadin JA, Richardson JE, Mouse Genome Database Group: The Mouse Genome Database (MGD): comprehensive resource for genetics and genomics of the laboratory mouse. Nucleic Acids Res 2012, 40(Database issue):D881-886.

doi:10.1186/1471-2164-14-62

Cite this article as: Barbagallo et al:: miR-296-3p, miR-298-5p and their downstream networks are causally involved in the higher resistance of mammalian pancreatic a cells to cytokine-induced apoptosis as compared to $\beta$ cells. BMC Genomics 2013 14:62.

\section{Submit your next manuscript to BioMed Central and take full advantage of:}

- Convenient online submission

- Thorough peer review

- No space constraints or color figure charges

- Immediate publication on acceptance

- Inclusion in PubMed, CAS, Scopus and Google Scholar

- Research which is freely available for redistribution 